\title{
How long did it take to get to the inflection point?
}

\author{
Minh- Hoang Nguyen \\ Ritsumeikan APU
}

23 October 2021

\begin{abstract}
$* * *$
It always strikes me whenever I ask myself the question: How long does it take for me to get a complicated job done. Most of the time, I do not have an answer.

Perhaps, it will be somewhat easier if one looks back upon the past. And suddenly, I am in a position to answer that question for a specific happening, called an inflection point. It is the advent of the Bayesian mindsponge framework or BMF for short [1].

For the BMF, something proposed and backed up by a dozen published research articles, I have reached this inflection point within some 33 months, counting the milestone of my first- ever academic publication [2]. However, that time span appears to have fallen short of the reality because the mindsponge concept had taken its initiators some four years before my seriously absorbing it. For this specific thought, I am referring to such publications as [3-4].

And, the mindsponge itself had been distilled during the far distant path back in the early 2000s due to its main author's theoretical considerations [5-6]. I was told that for these two works to become complete manuscripts, they had spent some 12 months at the least.
\end{abstract}

Therefore, I believe that the actual time spent has collectively been at least 17 years! A serious accounting job will probably show that the actual time could easily reach 20 years.

Apparently, as a 26- year- old Ph.D. candidate, I don't have that many years! I had little choice but to borrow much of that from the senior authors. They have helped to set my learning curve much steeper than I had had to do that myself. So my idea of the BMF has benefited from a huge reduction of costs, thanks to my ability to avoid the roller- coaster ride. Thus, the saved costs should be able to be converted to some expected profits.

Now all this thinking has led to another serious question for me to answer: 
How long more will I need to implement the research program that can successfully introduce the BMF to the world?

Frankly, the question is too difficult to answer. I just hope that it will not take so long that this very question is cleanly forgotten by the time the answer comes up. I can be sure that by 2031 , I will no longer remember that I have written something like this today.

\section{References}

[1] Nguyen, M.- H., \& Le, T.- T. (2021). Bayesian Mindsponge Framework. Encyclopedia. Retrieved from: https:// encyclopedia.pub/ 13852 (accessed: 23 October 2021)

[2] Nguyen, M. H., Le, T. T., \& Meirmanov, S. (2019). Depression, acculturative stress, and social connectedness among international university students in Japan: a statistical investigation. Sustainability, 11(3), 878.

[3] Vuong, Q. H., \& Napier, N. K. (2015). Acculturation and global mindsponge: an emerging market perspective. International Journal of Intercultural Relations, 49, 354- 367.

[4] Vuong, Q. H. (2016). Global mindset as the integration of emerging sociocultural values through mindsponge processes. In: J. Kuada (Ed.). Global Mindsets: Exploration and Perspectives (pp. 109- 126). London, UK: Routledge.

[5] Van Huu, N., Hoang, V. Q., \& Ngoc, T. M. (2005). Central limit theorem for functional of jump Markov processes. Vietnam Journal of Mathematics, 33(4), 443- 461.

[6] Van Huu, N., \& Hoang, V. Q. (2007). On the martingale representation theorem and on approximate hedging a contingent claim in the minimum deviation square criterion. In: R. J eltsch, T- T. Li \& I. H. Sloan (Eds.) Some Topics in Industrial and Applied Mathematics (pp. 134- 151). Hackensack, New J ersey: World Scientific. 